\title{
Análise do valor engadido dun novo envase no mercado de azucre e a súa influencia na disposición a pagar
}

\author{
Domingo Calvo Dopico / Ángel María del Castillo Puente ${ }^{\mathrm{b}}$ / Jonathan Herrera Peña*c 1 \\ a Universidade da Coruña - Facultade de Economía e Empresa \\ b EAE Business School Madrid \\ c Universidad Técnica de Machala - Facultad de Ciencias Empresariales - Ecuador
}

Recibido: 30 de marzo de 2020 / Aceptado: 11 de maio de 2020

\section{Resumo}

No ano 2007 a empresa Azucarera lanzou con éxito un novo envase de azucre co obxecto de mellorar a diferenciación do produto. Doce anos despois de sacar o novo produto preténdese analizar cal é a valoración dos atributos do envase que lle engaden valor, a intención de compra e a disposición a pagar un sobreprezo polo novo envase fronte ao envase orixinal. A partir do coñecemento obtido tras o lanzamento do produto, este estudo analiza, ademais do punto de vista do consumidor, o do fabricante do envase, o do distribuidor e mais o da empresa produtora do azucre. Os resultados revelan que o consumidor está disposto a pagar un sobreprezo fronte ao envase tradicional, ademais de valorar significativamente as principais calidades do envase como son a funcionalidade, a hermeticidade e a hixiene.

\section{Palabras clave}

Comportamento da consumidor / Innovación / Azucre / Agroindustria / Márketing.

\section{Analysis of perceived value of a new packaging in sugar market and its influence on willingness to pay}

\begin{abstract}
In 2007, the Azucarera company successfully launched a new sugar container in order to improve product differentiation. Twelve years after launching the new product, the aim is to analyze the evaluation of the attributes of the packaging that add value to it, the intention to buy and the willingness to pay a premium for the new packaging compared to the orixinal one. Based on the expertise obtained after the launch of the product, this study analyzes, in addition to the consumer's point of view, the manufacturer of the container, the distributor and the company that produces sugar. The results reveal that the consumer is not only predisposed to buy the new package but is willing to pay price premium over the traditional package in addition to significantly assessing the main dimensions of the package such as ease of use, tightness and hygiene.
\end{abstract}

\section{Keywords}

Consumer behaviour / Innovation / Sugar / Agro food industry / Marketing.

JEL Codes: M310, 0310, Q130.

\section{Introdución}

A maior esixencia e preocupación pola calidade, a saúde e o menor tempo que se dedica á preparación dos alimentos supoñen novos retos para as empresas establecidas no sector agroalimentario. Este feito vese agravado pola maior competencia e pola entrada de novos operadores motivada por unha maior globalización da actividade económica. Ante este novo escenario as empresas deben ofrecer

\footnotetext{
* Correspondencia autor: jherrera@utmachala.edu.ec

1 Os autores queren agradecer os comentarios de expertos do mercado do azucre refinado e a colaboración da Dirección de Márketing de Azucarera.
} 
produtos de maior valor para o consumidor. 0 mercado do azucre representa moi ben este escenario.

Os hidratos de carbono son un ingrediente fundamental nas dietas de consumo. Non obstante, cada vez existen maiores freos ao seu consumo debido a novas preocupacións dietéticas (Van dean Berg, 2011); á asociación desta categoría cun produto pouco saudable (Belkova et al., 2017); ou á aparición de novos produtos substitutivos como a sacarina ou os edulcorantes (Kamarulzaman, Jamal, Vijayan e Ab. Jalil, 2014), a pesar de que estes produtos presenten un sabor artificial e pouco natural. Por iso, faise necesario investigar o desenvolvemento de novos produtos no sector azucreiro que se adapten mellor ás novas preferencias dos consumidores. Doutra banda, o azucre presenta certos inconvenientes como son a falta de hermeticidade -por exemplo, envases que precisan que os produtos deban ser pasados a outro recipiente-, a dificultade de conservalos -por exemplo, ao abrilos pode caer o seu contido-, que non son funcionais -son incómodos para abrir- ou, mesmo, que rompen con facilidade.

Ao detectar estes problemas, a empresa española Azucarera decidiu desenvolver un novo envase para as variedades de azucre que comercializa. En concreto, tratábase de investigar a aceptación da tecnoloxía de envasado en brik. A Dirección Xeral da empresa Azucarera abordou o reto de lanzar un novo envase de azucre no mercado. Este proceso foi encabezado polo director de Márketing da compañía. A idea foi desenvolvida dentro do Departamento de Márketing da empresa e contou coa colaboración da empresa Elopak. 0 produto foi desenvolvido e lanzado con éxito.

Doce anos despois do lanzamento do envase (2007), preténdese analizar e identificar con precisión as dimensións de valor do envase do azucre, así como a influencia na intención de compra e na disposición a pagar. 0 target prioritario que se vai analizar son os consumidores menores de 35 anos. En concreto, este segmento posúe a taxa de consumo per cápita anual máis reducida en España, cun valor de 2,26 kg, fronte ao 3,31 kg de media (Ministerio de Agricultura, Pesca e Alimentación [MAPA], 2019). Por esta razón, o envase lanzado ao mercado tivo un contido de azucre menor que o envase tradicional, que nese ano 2007 representaba case a totalidade das vendas de azucre (bolsa de papel de $1 \mathrm{~kg}$ ). Ademais, este test tamén se fai necesario pola entrada de novos operadores no mercado, a aparición de marcas de distribuidor e a capacidade de negociación cada vez maior dos distribuidores, o cal incrementou a competencia nos prezos.

Doutra banda, o estudo pode identificar novas dimensións de valor, isto é, novas fontes de valor para esta categoría de produto. Por iso, a contribución deste estudo é notable. En primeiro lugar, ademais de mostrar un caso real de estudo, permitiu identificar importantes retos e oportunidades comerciais en materia de envasado da industria azucreira. En segundo lugar, trátase de contrastar se nun produto de escaso valor o consumidor está disposto a pagar por novos atributos ou funcionalidades.

0 documento está organizado como segue. Primeiramente, co obxecto de comprender o proceso de innovación e desenvolvemento do novo produto, explícanse as súas fases e, en concreto, a pretensión de replicar de novo o test de produto do novo envase, o cal xa fora realizado no ano 2007. A continuación, explícase a metodoloxía que se seguiu para realizar a investigación do mercado, tanto a fase cualitativa como a cuantitativa. Posteriormente, vanse analizado os resultados do test de envase. Finalmente, extráense as principais implicacións empresariais e expóñense as conclusións e futuras liñas de investigación.

\section{Marco conceptual}

\subsection{Modelización do proceso de desenvolvemento de novos produtos}

O modelo de referencia que se seguiu para o desenvolvemento do novo envase baseouse no modelo de "etapas e portas" (Stage-Gate® Systems) desenvolvido por Cooper (1990). Son modelos que perseguen ofrecer unha resposta a un mercado cada vez máis competitivo e cambiante, que encaixa no novo 
escenario ao que se enfrontan as empresas. En esencia, trátase dun sistema formalizado de actividades e decisións que serve como guía desde a aparición da idea de produto ata o seu lanzamento (Fernández del Hoyo, 2009). Desta forma, garántese que o deseño do produto se adapte ao que o mercado necesita. 0 proceso proposto é secuencial, aínda que presenta unha orientación interfuncional tanto nas accións (etapas) como nas decisións (portas). A importancia deste modelo no proceso de desenvolvemento de novos produtos foi moi notable, posto que non só se limita ou circunscribe ás grandes empresas senón tamén ás empresas medianas, ás pequenas ou mesmo ás microempresas (Howieson, Lawley e Selen, 2014). A continuación, explícanse de forma moi sintética as principais fases dos modelos de etapas e portas.

0 modelo de etapas e portas establece diferentes fases, que polo xeral adoitan ser cinco. A entrada a cada etapa é unha porta que fai de control de calidade e de pase -ou non pase- da idea de novo produto (Cooper, 1994). Cada etapa ten como obxectivo solicitar a información necesaria para o pase á seguinte porta. Seguindo a Fernández del Hoyo (2009), pode explicarse e sintetizar brevemente o proceso. Primeiramente, na investigación preliminar un grupo moi reducido de persoal técnico e de márketing realiza unha primeira análise do mercado e das necesidades técnicas, que posibilita unha valoración preliminar do negocio. A continuación, realízase unha investigación en profundidade que inclúe: i) unha investigación de mercado das necesidades e que identifique as demandas do perfil ideal do produto; ii) a análise da competencia; e iii) un concepto sobre o produto que desenvolver. Adicionalmente, debería incluírse un informe financeiro e de negocio. A partir da información proporcionada nesta fase sobre o concepto de produto, realizarase o deseño e o desenvolvemento do novo produto, que se materializará nun prototipo. Se o prototipo consegue superar o tests de produto e de mercado, isto é, se é aceptado polo consumidor final en condicións reais de mercado, decidirase o paso ao lanzamento (última porta) para a súa posterior comercialización (última etapa) (ver Figura 1).

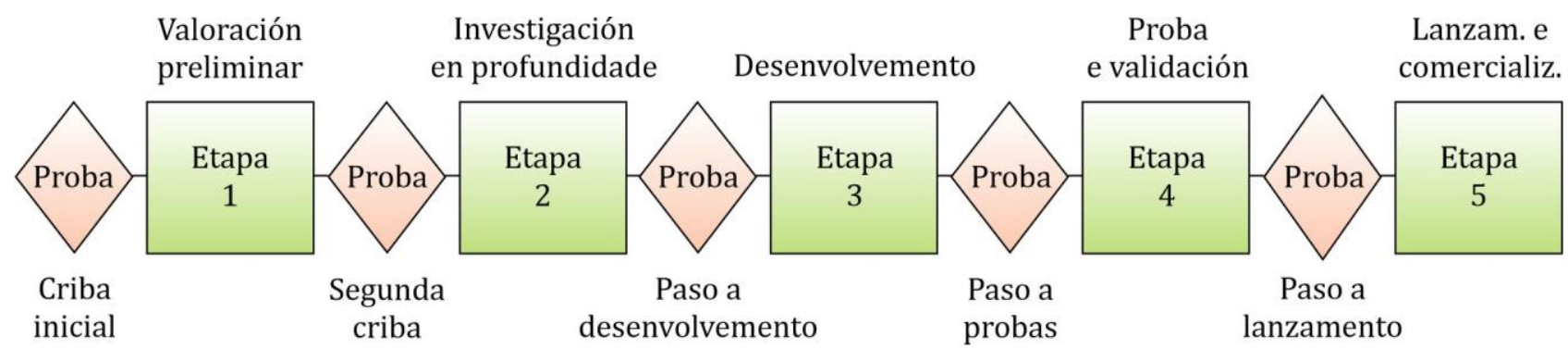

Figura 1. Modelo de etapas e portas. Fonte: Cooper (1990).

\subsection{Análise das preferencias e a súa importancia no desenvolvemento de novos produtos agroalimentarios}

A análise das preferencias permitirá realizar un estudo moi preciso da viabilidade comercial e adicionalmente pode proporcionar información moi útil para avaliar a viabilidade técnica e financeira (Calvo Dopico, Tudoran e Olsen, 2010). No que se refire á viabilidade comercial, isto é, a investigación da aceptación ou rexeitamento do produto ou dalgún dos seus atributos, a investigación das preferencias cobra unha gran relevancia. Diversos traballos previos que abordaron o estudo e investigación agroalimentaria (Steenkamp, 1986, 1993; Wierenga, 1983) preocupáronse en analizar esas dimensións, as cales determinan a preferencia global por un produto.

A literatura previa identificou diferentes dimensións. Entre elas, destaca a dimensión sensorial ou organoléptica, que inclúe as propiedades sensoriais do produto, como o sabor, a cor, o aroma, a textura ou a aparencia física. Esta dimensión sensorial está asociada e vinculada directamente coa dimensión hedónica. Numerosos estudos desenvolvidos con diferentes categorías de produto teñen concluído que 
esta dimensión é a que máis influencia ten á hora de explicar a aceptación do produto agroalimentario (Bello Acebroun e Calvo Dopico, 2000; Charters e Pettigrew, 2003; Jiménez-Guerreiro, Gázquez-Abad, Hortas-García e Mondéjar-Jiménez, 2012; Steenkamp, 1986).

Ademais, tamén se atopa a dimensión instrumental do produto (Wierenga, 1983). No caso dos beneficios instrumentais referímonos a beneficios como a facilidade de conservación, a facilidade de manexo, a facilidade de preparación ou a facilidade de consumo. Convén destacar que os beneficios instrumentais ou funcionais poden referirse ao produto en si mesmo ou a outros atributos, como pode ser o envasado.

Outra das dimensións á que cada vez se lle está prestando máis atención é a saúde. Desde un punto de vista do consumidor, os beneficios sobre a saúde dun produto agroalimentario engloban diferentes aspectos: efecto saudable, benestar, san, beneficio dietético ou valor nutricional. Os estudos de Barrena e Sánchez (2010) ou de Chironi, Bacarella, Altamore e Ingrassia (2017) coinciden en destacar a saúde como o principal beneficio nos produtos ecolóxicos ou nos produtos locais (Arsil, Li, Bruwer e Lyons, 2014), aínda que este último inclúe tamén a variable aforrar diñeiro. Igualmente, destacan os estudos de Olsen, Scholderer, Brunsø e Verbeke (2007) e de Rojas-Méndez, Le Nestour e Rod (2015), quen analizan a importancia da variable consciencia da saúde como factor determinante para explicar a demanda de produtos agroalimentarios pesqueiros por motivos de saúde.

Finalmente, aparece a dimensión simbólica, que recollería as referencias cara a atributos intanxibles como a simboloxía vinculada á orixe do produto, a marca ou as garantías, ou tamén a expresión persoal do propio axente. A orixe é un atributo que ten moita influencia sobre a imaxe que o consumidor se forma na súa mente (Min Han, 1989). Así, nalgúns estudos (Ingrassia, Sgroi, Tudisca, e Chironi, 2017; Tiozzo, Mari, Ruzza, Crovato e Ravarotto, 2017) sinálase que a conexión das propiedades sensoriais coa orixe do produto proporcionan unha maior confianza.

Estas preferencias veñen influídas por motivos ou estados de ánimo, por factores socioculturais ou situacionais ou por crenzas. Na medida en que as diferentes características ou propiedades do produto agroalimentario se adapten ás preferencias do consumidor, este mostrará a súa satisfacción -ou insatisfacción-, que influirá na intención de compra ou de consumo. Por iso, faise imprescindible investigar polo miúdo e en profundidade as preferencias do consumidor. Entre as diferentes aproximacións e métodos que se consideraron para abordalas destaca o test de concepto e o test de produto. 0 test de produto permite obter información moi valiosa sobre o grao de aceptación do produto por parte do consumidor, así como dos seus gustos, actitudes, valores ou estilos de vida. Na medida en que as diferentes dimensións do produto (sensorial, instrumental, saúde ou de imaxe) se adapten ás preferencias do consumidor, este proporcionaralle satisfacción, o que influirá de maneira positiva na intención de compra ou na disposición a pagar (Zeithaml, 1988). De igual maneira, se estas dimensións non se adaptan ás preferencias do consumidor, xerará insatisfacción, o que influirá de forma negativa na intención de compra (Figura 2).

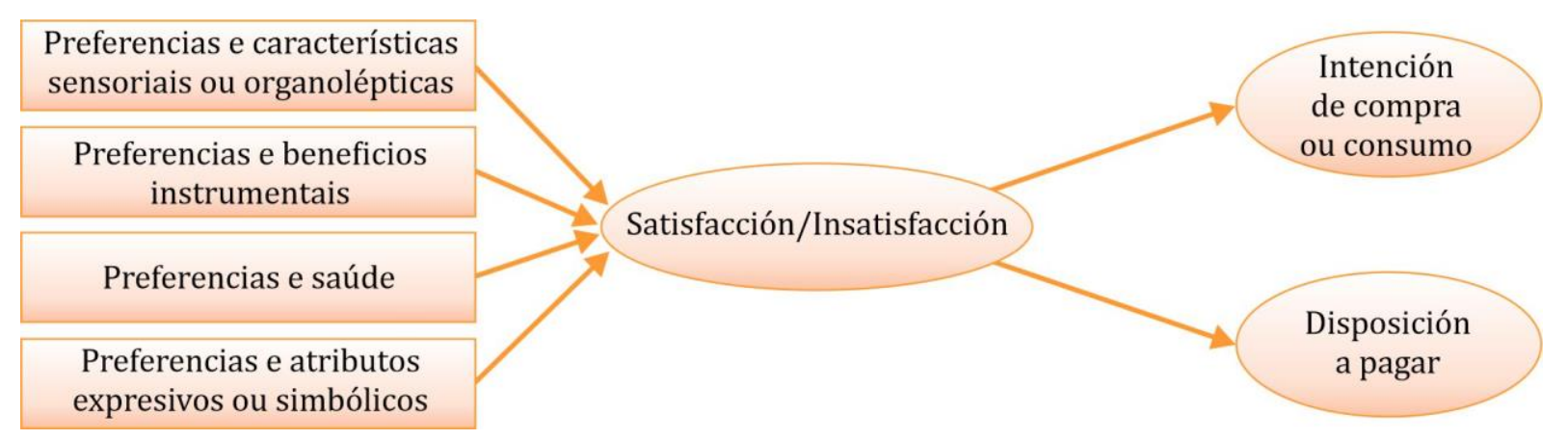

Figura 2. Dimensións das preferencias de produtos agroalimentarios e a súa relación coa satisfacción e intención de compra e/ou a disposición a pagar. Fonte: elaboración propia. 


\section{Metodoloxía}

\subsection{Investigación cualitativa}

Os desenvolvementos posteriores do modelo de Cooper destacan a necesidade de integrar os intereses dos diferentes axentes que interveñen no proceso de creación do novo envase. Esta foi unha das claves do éxito do lanzamento do novo envase, e que se explica a continuación. Desta maneira, ademais de analizar o rol do consumidor, inclúese a análise do provedor e o do distribuidor. A continuación, explícase a investigación cualitativa -que incluiría as fases de valoración preliminar e de investigación en profundidade do modelo de Cooper (1990)- que se realizou cando se desenvolveu con éxito o produto, así como a investigación derivada da opinión de expertos, tanto de directivos como de distribuidores.

\subsubsection{Valoración preliminar}

Na identificación dos atributos para o desenvolvemento dun novo envase a Dirección de Márketing de Azucarera identificou a necesidade de comprender a opinión do tres stakeholders fundamentais -ou partes interesadas- para poder abordar con éxito un novo envase que xerase unha maior intención de compra e unha predisposición a pagar un incremento no prezo fronte ao envase tradicional (azucre branco papel $1 \mathrm{~kg}$ ). Este tres stakeholders foron os consumidores, o provedor e o cliente ou distribuidor.

En primeiro lugar, analizouse o consumidor. Para iso, na primeira fase do modelo teórico exposto, a Dirección de Márketing de Azucarera decidiu comezar cun benchmarking. Isto permitiu entender a satisfacción -ou a insatisfacción- dos consumidores cos distintos tipos de envases actuais de alimentación, de modo que se podería avaliar as achegas de posibles novos envases á categoría azucre, así como valorar a predisposición á compra e os seus motivos. Para este fin, a Dirección de Márketing solicitou información relativa aos problemas que presentan os envases actuais así como aqueles atributos mellor considerados, co obxecto de poder adaptar os envases máis valorados á categoría azucre.

A continuación, decidiu analizar a percepción da categoría azucre, as perspectivas de evolución e a percepción e valoración dos envases de Azucarera por parte dos seus clientes. Para a consecución deste obxectivo, contou coa información do Customer Relationship Management (CRM) relativa ás reunións mantidas cos directores de compra das principais cadeas de distribución en España que absorben máis do $50 \%$ das vendas de azucre do país. As cadeas de distribución coas que se traballou foron Mercadona, Carrefour, Dia, Grupo Eroski, Caprabo, Gadisa, El Árbol, Ahold e Supermercados Moldes.

En segundo lugar, estudouse o provedor. Nun ambiente moi competitivo, un produto de primeira necesidade cunha alta frecuencia de compra como é o azucre necesita contar cun provedor que se involucre no proxecto en dúas dimensións: tecnolóxica e custos. No que se refire á dimensión tecnolóxica, co obxecto de facer posible o envasado de azucre nun novo formato; e polo que respecta á dimensión de custos, co obxectivo de que o novo envase poida chegar ao momento de venda a un prezo de venda ao público atractivo no lineal e que o comprador de azucre estea disposto a asumir. En canto á selección do provedor, finalmente a Dirección de Márketing de Azucarera, despois de manter distintas reunións con provedores de brik , decidiu que o provedor Elopak era o que mellor cumpría os catro criterios fixados para a súa selección: fiabilidade, credibilidade, modernidade e competitividade.

En terceiro lugar, analizouse o distribuidor ou retailer. Nun sector moi concentrado (Yagüe Guillén, Cruz Roche e Rebollo Arévalo, 2003), a colaboración dos distribuidores tamén se fai imprescindible (Gruen e Shah, 2000), xa que sen ela a accesibilidade por parte dos compradores de azucre ao novo packaging faise imposible ao non estar referenciada nos principais distribuidores nacionais. 0 poten- 
cial efecto da substitución ou canibalización do envase tradicional polo brik debe conducir a unha mellora da rendibilidade por parte dos distribuidores, necesaria para conseguir a viabilidade económica (Cruz Roche, 1999). En definitiva, un dos factores do éxito da aceptación deste envase reside na colaboración dos diferentes actores que interveñen no proceso (provedor, fabricante e distribuidores). Unha vez desenvolvida esta fase preliminar, explícase sinteticamente en que consistiu a investigación en profundidade.

\subsubsection{Investigación en profundidade. Dimensións clave do novo envase de azucre}

Na investigación en profundidade preténdese identificar as dimensións clave sobre as que se pode abordar o desenvolvemento do prototipo do novo envase. Desde a Dirección de Márketing de Azucarera, coa información obtida do benchmarking realizado, das reunións con provedores e distribuidores e do coñecemento obtido do proceso de innovación e desenvolvemento do ano 2007, identificáronse os atributos que poderían mellorarse no novo envase. Con todo, non estaba claro cales eran as dimensións de valor sobre as que había que actuar. Tras revisar o modelo de Cooper, a literatura sobre innovación e desenvolvemento de produtos agroalimentarios e as preferencias do consumidor (epígrafes 2.1 e 2.2), si que puideron ser identificadas, as cales se explican con detalle no epígrafe de resultados.

\subsection{Investigación cuantitativa}

Ademais desta fase cualitativa, levouse a cabo a investigación cuantitativa na que se analizaron tres cuestións: a avaliación por parte dos consumidores dos atributos que confiren valor tanto para o envase tradicional como para o novo envase, a intención de compra do envase tradicional e do novo envase e a disposición a pagar un sobreprezo polo novo envase fronte ao envase tradicional. Como xa se explicou na Introdución, o que se pretende analizar, doce anos despois de lanzar o produto, é a valoración dos atributos que lle confiren valor, así como a intención de compra e a disposición a pagar por parte dos consumidores, especialmente o público obxectivo: os máis novos. Atopámonos ante unha nova contorna na que hai máis competencia e onde as marcas de distribuidor teñen un peso moi importante. Neste nova contorna quérese saber se se mantén por parte do consumidor a predisposición a pagar un sobreprezo polo novo produto. Nas Figuras 3 e 4 pódense visualizar os dous produtos investigados.

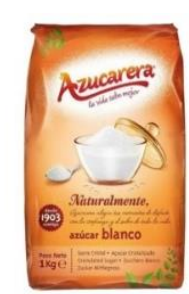

Figura 3. Envase tradicional de azucre branco

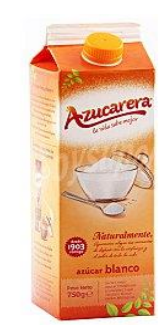

Figura 4. Novo envase de azucre

\subsubsection{Traballo de campo}

O universo poboacional estivo formado por consumidores e mais por responsables da compra final de azucre branco no mercado español, de entre 24 e 65 anos, e que consumisen azucre branco no último ano.

Na primeira cuestión formuláronse diferentes preguntas filtro co obxecto de identificar ben o público obxectivo. En primeiro lugar, que só incluíse residentes de España; en segundo lugar, que consu- 
mise azucre branco no fogar no último ano; en terceiro lugar, que participara nun grupo de discusión relacionado co consumo do azucre. Se a algunha destas preguntas respondía que non, non podería participar no estudo. Do mesmo xeito, para evitar nesgos nas respostas, tampouco se admitiu que os consumidores participantes tivesen algún membro da súa familia ou dos seus amigos próximos traballando na venda, comercialización ou distribución de azucre ou de edulcorantes.

Realizouse un cuestionario estruturado en hall-test na Praza de Día na cidade de Madrid. Foi dirixido a 201 consumidores e tivo lugar entre os meses de novembro e decembro de 2018. 0 prezo que se tomou como referencia foi o prezo real da bolsa de papel de $1 \mathrm{~kg}$ vixente nese momento, que era de $0,69 € / \mathrm{kg}$ (actualmente é de $0,79 € / \mathrm{kg}$ ).

\subsubsection{Organización do cuestionario. Variables seleccionadas e tipos de escala}

Primeiramente, preguntóuselles sobre os hábitos de compra de azucre. A continuación, fixéronse as preguntas para avaliar os diferentes atributos que lle confiren valor ao produto, as cales foron medidas consonte unha escala Likert, onde a avaliación mínima era 1, que indicaba "moi mala", mentres que o valor máximo era 7, e indicaba "moi ben".

A intención de compra mediuse usando igualmente unha escala Likert. Neste caso, a avaliación mínima foi 1, que estaba definida por "definitivamente non o comprarei", mentres que o valor máximo foi 7, que estaba definida pola categoría "definitivamente, comprareino".

Finalmente, pedíuselles a disposición a pagar polo envase brik, tendo en conta que actualmente a embalaxe de azucre branco en papel é de $0,69 € / \mathrm{kg}$. A pregunta que se fixo foi a seguinte: tendo en conta que o prezo de compra do paquete de azucre branco papel é de $0,69 € / \mathrm{kg}$, que prezo estaría disposto a pagar polo brik de azucre branco? 0 consumidor debía responder en $€ / \mathrm{kg}$. Con esta proposición o que se quería contrastar é se na actualidade os consumidores están dispostos a pagar un sobreprezo polo novo envase, tomando como referencia o prezo do envase tradicional.

As preguntas foron revisadas previamente por expertos en márketing, que avaliaron a ambigüidade de cada pregunta e a capacidade de cada enquisado para respondelas. Para a medición da importancia dos diferentes atributos do envase optouse por escalas de diferencial semántico (Russell, 2010), e para analizar a intención de compra seguiuse o estudo de Tam (2004). Para a medición dos hábitos de compra de azucre branco recorreuse a introducir a frecuencia de compra.

Na Táboa 1 poden observarse os obxectivos da investigación cuantitativa, así como as variables e as escalas utilizadas.

Táboa 1. Obxectivo formulado, variables identificadas e preguntas formuladas no cuestionario

\begin{tabular}{lll}
\hline Obxectivo & Variables identificadas & Pregunta formulada e tipo de escala utilizada \\
\hline $\begin{array}{l}\text { Analizar os } \\
\text { hábitos de } \\
\text { compra de }\end{array}$ & $\begin{array}{l}\text { Hábitos de compra de azucre } \\
\text { branco. }\end{array}$ & $\begin{array}{l}\text { Indique con que frecuencia compra o azucre branco pa- } \\
\text { ra o seu fogar: }\end{array}$ \\
& $\begin{array}{l}\text { 1. Menos dunha vez ao mes. } \\
\text { 2. Unha vez ao mes. } \\
\text { 3. Cada mes e medio. } \\
\text { 4. Unha vez cada dous meses. } \\
\text { 5. Unha vez cada tres meses. } \\
\text { 6. Unha vez cada catro meses. } \\
\text { 7. Unha vez cada cinco meses. } \\
\text { 8. Unha vez cada seis meses. } \\
\text { 9. Unha vez cada oito meses. } \\
\text { 10. Unha vez ao ano. }\end{array}$ \\
\end{tabular}


Táboa 1 (continuación). Obxectivo formulado, variables identificadas e preguntas formuladas no cuestionario

\begin{tabular}{|c|c|c|}
\hline Obxectivo & Variables identificadas & Pregunta formulada e tipo de escala utilizada \\
\hline $\begin{array}{l}\text { Avaliar a } \\
\text { importancia dos } \\
\text { atributos que lle } \\
\text { confiren valor*. }\end{array}$ & $\begin{array}{l}\text { FUNCIONALIDADE (DE USO) } \\
\text { - Facilidade de pasar o azucre a } \\
\text { outro } \\
\text { recipiente (azucreiro, tarro). } \\
\text { - Facilidade de apertura. } \\
\text { - Posibilidade de peche despois de } \\
\text { aberto. } \\
\text { - Comodidade ao sostelo na man. } \\
\text { HERMETICIDADE } \\
\text { - Resistente. } \\
\text { - Conservación do azucre. } \\
\text { - Impermeabilidade. } \\
\text { HIXIENE } \\
\text { - Envase hixiénico. }\end{array}$ & $\begin{array}{l}\text { 1.- Vendo estes dous envases (envase de bolsa de papel } \\
\text { e envase brik), valore segundo a súa opinión os diferen- } \\
\text { tes atributos que lle indicamos a continuación: } \\
\text { 1. Moi mal. } \\
\text { 2. Bastante mal. } \\
\text { 3. Algo mal. } \\
\text { 4. Nin ben nin mal. } \\
\text { 5. Algo ben. } \\
\text { 6. Bastante ben. } \\
\text { 7. Moi ben. }\end{array}$ \\
\hline $\begin{array}{l}\text { Analizar a } \\
\text { intención de } \\
\text { compra. }\end{array}$ & Intención de compra. & $\begin{array}{l}\text { Indique a intención de compra de cada un destes enva- } \\
\text { ses (envase de bolsa de papel e envase brik): } \\
\text { 1. Definitivamente non o comprarei. } \\
\text { 2. Bastante improbable que o compre. } \\
\text { 3. Pouco probable que o compre. } \\
\text { 4. Nin probable nin improbable. } \\
\text { 5. Algo probable que o compre. } \\
\text { 6. Bastante probable que o compre. } \\
\text { 7. Definitivamente, comprareino. }\end{array}$ \\
\hline $\begin{array}{l}\text { Analizar a } \\
\text { disposición a } \\
\text { pagar. }\end{array}$ & $\begin{array}{l}\text { Disposición a pagar (prezo de } \\
\text { venda do envase de bolsa de azu- } \\
\text { cre e do envase brik). }\end{array}$ & $\begin{array}{l}\text { Tendo en conta que o prezo de compra do paquete de } \\
\text { azucre branco papel é de } 0,69 € / \mathrm{kg} \text {, que prezo estaría } \\
\text { disposto a pagar polo brik de azucre branco? ( } 0 \text { consu- } \\
\text { midor debía responder en } € / \mathrm{kg} \text { ). }\end{array}$ \\
\hline
\end{tabular}

Nota: *Tras a revisión da literatura sobre investigación agroalimentaria, precisáronse e definíronse moito mellor non só cales deberían ser eses atributos senón tamén as dimensións de valor subxacentes. Aparecen en maiúscula. Fonte: elaboración propia.

\subsubsection{Estrutura da mostra}

Entre as diferentes variables que o MAPA define para conseguir identificar mostras representativas está a variable tipo de fogar. 0 obxectivo deste estudo centrouse maioritariamente no público obxectivo novo, por iso será este segmento o máis numeroso $(70,6 \%)$-cunha franxa de idade comprendida entre os 23 e os 34 anos-. Para este segmento, o MAPA define diferentes perfís de fogar: parellas novas sen fillos e fogares unipersoais (adultos independentes ou mozos independentes). Como se pode ver, o resto dos segmentos (entre 35 e 44 anos e entre 45 e 54 anos) son de menor tamaño: un 15,5\% e un $12 \%$, respectivamente.

Na Táboa 2 pode observarse como ambos os perfís sociodemográficos foron recollidos na mesma categoría. A razón pola que se escolleu este segmento de idade como prioritario foi o feito de que nos estudos do MAPA (2019) se identificou como o posuidor da taxa de consumo per cápita anual máis reducida en España, cun valor de 2,26 kg fronte ao 3,31 kg de media. Esta cuestión foi explicada na Introdución. A estrutura da mostra engloba a proporción maioritaria de consumidores formada por fogares menores de 35 anos (71\%) (Táboa 2). Este criterio sociodemográfico cumpre cos requisitos esixidos polo estudo. 
Táboa 2. Estrutura sociodemográfica da mostra

\begin{tabular}{lc}
\hline Idade & $\begin{array}{c}\text { Frecuencia } \\
\text { relativa }\end{array}$ \\
\hline Entre 23 e 34 anos & $70,6 \%$ \\
Entre 35 e 44 anos & $15,5 \%$ \\
Entre 45 e 54 anos & $12 \%$ \\
Máis de 55 anos & $1,9 \%$ \\
TOTAL & $100 \%$ \\
Xénero & $55 \%$ \\
Home & $45 \%$ \\
Muller & $100 \%$ \\
TOTAL & \\
Tipoloxía do fogar & $78 \%$ \\
Fogares unipersoais (mozos independentes ou adultos independentes) ou parellas sen fillos & $12 \%$ \\
Parella con fillos menores de doce anos que viven na casa & $9 \%$ \\
Parella con fillos maiores de doce anos que viven na casa & $1 \%$ \\
Parella con fillos maiores que xa non viven no fogar & $100 \%$ \\
TOTAL & \\
\hline
\end{tabular}

Fonte: elaboración propia.

\section{Resultados}

Distínguense os resultados de ambas as fases de estudo. En primeiro lugar, explícanse os resultados da fase cualitativa na que se analiza a percepción do envase por parte dos consumidores e distribuidores, e a continuación aparecen os datos da fase cuantitativa na que se ofrecen os resultados dos hábitos de compra e da valoración dos atributos que lle confiren valor, a intención de compra e a disposición a pagar.

\subsection{Percepción do envase por parte de consumidores e distribuidores}

\subsubsection{Experiencia previa e revisión da investigación agroalimentaria}

A partir do coñecemento e da aprendizaxe obtidos do lanzamento do novo envase no ano 2007, púidose contrastar que entre as principais críticas dos envases de papel de azucre destacaban, por esta orde, as seguintes: "ao abrilos cáelles o contido", "deben ser pasados a outro recipiente", "rompen con facilidade" e "son incómodos para abrir e almacenar".

Doutra banda, a análise benchmarking dos beneficios potenciais de envases de alimentos con tecnoloxía brik presentaba unha valoración positiva centrada nos seguintes beneficios: "prácticos", "funcionais", "resistencia", "manteñen a calidade do produto", "boa imaxe xeral como envases" e "modernos".

Con todo, é preciso identificar de forma precisa as dimensións ou as fontes de valor. Para iso, recorreuse á revisión da literatura. En concreto, identificáronse tres beneficios principais: funcionalidade ou practicidade no uso, hermeticidade e hixiene.

En primeiro lugar, destaca a funcionalidade. De feito, en diferentes casos os consumidores teñen dificultades para usar ou manipular o paquete de azucre, tanto para abrilo como para pechalo. En canto ao peche, o produto debe conservarse mellor unha vez aberto. En consecuencia, o envase debería ser moito máis práctico e funcional. En segundo lugar, require que o produto se almacene mellor, dado 
que ao abrilo o azucre perde calidade e, ademais, débese depositar noutro recipiente. Noutras palabras, o envase debe permitir o almacenamento do azucre mantendo as súas propiedades sensoriais, é dicir, que sexa unha embalaxe máis hermética, dado que o envase actual rompe facilmente. Este feito revelou a necesidade de protexer o produto moito máis e de garantir mellor as condicións de conservación. Ademais, o peche debe garantir as características do produto unha vez aberto o envase. En terceiro lugar, ademais dunha protección adecuada debe estar ben protexido internamente para que non dea a impresión de que se está deteriorando e evitar, por tanto, a sensación de sucidade. Trátase da dimensión da hixiene.

Xa que logo, e segundo esta información de carácter cualitativo, o novo envase debe cumprir coas expectativas dos consumidores, isto é, un envase máis hermético, máis práctico ou funcional e máis hixiénico. Estes resultados son coherentes cos fundamentos teóricos, polo que se pode concluír que a dimensión máis importante na que se debe centrar o desenvolvemento de novos envases de azucre é a dimensión instrumental ou funcional, ou ben aquela relacionada co valor en uso do produto.

\subsubsection{Percepción dos distribuidores}

No que se refire aos distribuidores, o azucre preséntase, por unha banda, como unha categoría que lle xera pouca rendibilidade á cadea e, por outra, como un produto necesario e presente en todos os fogares.

A súa evolución recente indica que se trata dunha categoría estancada, en leve descenso e á que se lle augura pouca evolución no curto prazo en caso de continuar coas actuais directrices de xestión da categoría. De feito, a distribución proxecta unha imaxe xeral da categoría desfavorable, que se fundamenta nas seguintes razóns: non se innova e mércase por inercia. Aínda que se traballen outras referencias, claramente a de maior rotación é a do azucre branco papel de 1 quilo, en tanto que as demais referencias apenas rotan, o que leva á distribución a considerar o azucre como un produto dunha única referencia.

Reclámase a reactivación da categoría mediante a innovación, valéndose da incorporación de elementos que lles doten valor engadido aos produtos. Trátase de espertar o interese do consumidor, o cal, en opinión do distribuidor, lle presta moi pouca atención á categoría, percibe nela un produto básico, homoxéneo, sen diferenciación, polo que non está disposto a pagar moito. Ademais, o propio distribuidor considéraa como unha categoría cuxo rol fundamental é a xeración de tráfico, é dicir, que as vendas en volume son altas (Blattberg, 1995) pero a marxe bruta baixa (Rouquet e Valenzuela Martínez, 1998).

Ante esta actitude por parte do consumidor, a escasa marxe que lles deixa a categoría ás cadeas de distribución e ante a súa percepción de pouca actividade do fabricante, o distribuidor non está predisposto a investir na categoría, senón que considera que debe ser o fabricante quen dea o primeiro paso para dinamizala. Así e todo, mostran unha actitude escéptica ante a posibilidade dun incremento do consumo de azucre, aínda que tamén se percibe unha certa confianza na posibilidade de desprazar o consumo cara a segmentos de maior valor engadido que axuden a incrementar o gasto e a marxe desta categoría.

Polo tanto, ante a evolución actual do mercado non se prevé un aumento do espazo dedicado á categoría. É máis, parece probable que a inclusión de novas referencias se leve a cabo á conta de eliminar algún facing ou unidade de presentación dun produto vista de fronte (Drèze, Hoch e Purk, 1994) das referencias existentes (Chernev, 2003). Para conseguir ampliar o espazo do azucre, tería que cambiar o rol da categoría. En xeral, dedícaselles un pequeno espazo ás especialidades pola súa baixa rotación, en tanto que o azucre branco papel de 1 quilo -que é a referencia estrela- ocupa un grande espazo e, pola súa alta rotación, adoita colocarse directamente en palés.

Por último, o distribuidor demanda novos formatos e tamaños máis adecuados ás necesidades dos seus clientes, como por exemplo formatos máis pequenos enfocados a fogares unipersoais. Con respecto ao envase de azucre branco papel de $1 \mathrm{~kg}$, o número de unidades por embalaxe valórase adecuado para tendas medianas e grandes, aínda que é excesivo para tendas menores de $200 \mathrm{~m}^{2}$, onde te- 
ñen que gardar caixas abertas en almacén cos consecuentes problemas que isto ocasiona en canto a hixiene, roturas e limitacións de espazo. Valórase favorablemente a unidade de venda en palé, que precisamente é máis satisfactoria porque evita roturas e, por tanto, custos de non calidade (Sansalvador Sellés, 2001) e derrames do produto (mellor hixiene), o que á súa vez permite mellorar o seu atractivo.

Entre os inconvenientes poden citarse os seguintes: que se percibe como un envase tradicional e anticuado, e o seu factor de resistencia, que podería mellorarse evitando que rache e que se verta o produto.

En suma, trátase de obter novos envases encamiñados a mellorar a súa resistencia e a impulsar a súa función de reclamo no lineal. Ademais, solicitan outros formatos e deseños acordes ás necesidades dos clientes. A empresa está en disposición de ofrecer unha oferta variada, ademais de nova, que se configura como un factor moi positivo ao explicar o mellor desempeño por parte dos distribuidores (Dhar, Hoch e Kumar, 2001).

En conclusión, determinouse que o novo envase brik fose de 800 gramos. As principais vantaxes con respecto ao azucre branco papel $1 \mathrm{~kg}$ fundaméntanse en diferentes aspectos, entre os que destacan a familiaridade no trasvase a outros recipientes, a mellora nas sucesivas aperturas e peches, a comodidade na súa manipulación e unha maior resistencia e impermeabilidade do envase que supón unha menor conservación do produto e hixiene. A redución da cantidade de azucre no envase tiña como obxecto adaptarse ao segmento de menores de 35 anos, xa que a súa taxa de consumo é bastante reducida $(2,26 \mathrm{~kg}$ fronte ao $3,35 \mathrm{~kg}$ de media). Por último, a dimensión de hermeticidade inclúe os atributos comentados polos distribuidores de resistencia e de evitar roturas.

\subsection{Hábitos de compra}

Tal e como se mostra na Táboa 3, non hai un patrón de compra único. Pódense identificar tres patróns de comportamento en función da regularidade da compra. En primeiro lugar, hai fogares que compran regularmente este produto; deles destacan aqueles que o fan cunha frecuencia dunha vez ao mes $(25,4 \%)$ ou dunha vez cada tres meses $(12,9 \%)$. En segundo lugar, detectamos un comportamento de compra de frecuencia media, que agruparía aquelas categorías cun consumo menos frecuente -unha vez cada catro-seis meses-, que representa o $16,5 \%$. Finalmente, hai un $27,9 \%$ cuxa frecuencia de compra é baixa, que incluiría aqueles fogares que o compran unha vez cada oito-once meses $(1,5 \%)$ ou unha vez ao ano $(26,3 \%)$.

Táboa 3. Hábitos de compra de azucre branco

\begin{tabular}{lcc}
\hline Frecuencia de compra & Porcentaxe (\%) & Porcentaxe acumulada (\%) \\
\hline Menos dunha vez ao mes & $0,5 \%$ & \\
Unha vez ao mes & $25,4 \%$ & \\
Cada mes e medio & $1,0 \%$ & $55,7 \%$ (alta frecuencia) \\
Unha vez cada dous meses & $15,9 \%$ & \\
Unha vez cada tres meses & $12,9 \%$ & \\
Unha vez cada catro meses & $6,0 \%$ & \\
Unha vez cada cinco meses & $2,0 \%$ & $16,5 \%$ (frecuencia media) \\
Unha vez cada seis meses & $8,5 \%$ & \\
Unha vez cada oito meses & $1,5 \%$ & $27,8 \%$ (frecuencia baixa) \\
Unha vez ao ano & $26,3 \%$ & \\
\hline
\end{tabular}

Fonte: elaboración propia. 


\subsection{Importancia dos atributos, intención de compra e disposición a pagar}

\subsubsection{Avaliación e comparación dos diferentes atributos}

Como se pode comprobar na Táboa 4, verificouse que en todos os atributos presentados aos consumidores a valoración do novo envase (brik) é superior fronte ao envase tradicional (bolsa de papel para o azucre branco). Así, para todos os atributos valorados a diferenza dos valores medios é estatisticamente significativa, feito que se pode comprobar ao ver que as diferenzas entre as puntuacións medias dos atributos que lle confiren valor ao envase son, en termos relativos, notables e nalgún caso sobresaliente.

Destacan, sobre todo, o peche do envase (diferenza de 4,35 puntos), un envase hixiénico (diferenza de 3,65 puntos), a resistencia (diferenza de 3,28 puntos) e a impermeabilidade (diferenza de 2,56 puntos). En todos os atributos valorados o nivel de significación é inferior ao $1 \%(p<0,01)$. Estes atributos poden mellorar notablemente o deseño do envase, o que permite unha mellora na súa capacidade competitiva (Azad e Masoumi, 2012) ao configurarse como un activo fundamental para competir nos mercados agroalimentarios (Rundh, 2009).

Táboa 4. Valoración dos atributos para o novo envase de azucre fronte ao envase tradicional e test de diferenza de medias ( $t$ student) $(n=201)$

\begin{tabular}{llccc}
\hline $\begin{array}{l}\text { Dimensión } \\
\text { de valor }\end{array}$ & $\begin{array}{l}\text { Atributos asociados } \\
\text { a cada dimensión }\end{array}$ & $\begin{array}{c}\text { Puntuación media } \\
\text { dos atributos } \\
\text { (envase brik) }\end{array}$ & $\begin{array}{c}\text { Puntuación media } \\
\text { dos atributos } \\
\text { (bolsa de papel) }\end{array}$ & $\begin{array}{c}\text { Diferenza } \\
\text { de medias }\end{array}$ \\
\hline $\begin{array}{l}\text { Practicidade e } \\
\text { funcionalidade }\end{array}$ & $\begin{array}{l}\text { Facilidade de pasar o azucre a outro } \\
\text { recipiente } \\
\text { Apertura do envase }\end{array}$ & 6,05 & 3,83 & $2,22^{*}$ \\
& $\begin{array}{l}\text { Peche do envase } \\
\text { Manexabilidade }\end{array}$ & 6,38 & 3,89 & $2,49^{*}$ \\
& Resistente & 6,73 & 2,38 & $4,35^{*}$ \\
Hermeticidade & Conservación do azucre & 6,04 & 3,76 & $2,28^{*}$ \\
& Impermeabilidade & 6,31 & 3,03 & $3,28^{*}$ \\
Hixiene & Envase hixiénico & 6,17 & 3,71 & $2,46^{*}$ \\
\end{tabular}

Nota: A diferenza de medias entre a valoración do atributo do envase brik e o envase tradicional é significativa en todos os casos $(p<0,01)$. Fonte: elaboración propia.

\subsubsection{Intención de compra}

Como se pode comprobar na Táboa 5, a media da intención de compra do novo envase (brik) é superior fronte ao envase tradicional. Por tanto, a diferenza entre a media da intención de compra da bolsa de papel e do novo envase brik en termos absolutos é importante $(2,33)$ e significativa $(p<0,01)$. Tamén destaca o feito de que o valor da desviación estándar no caso da intención de compra para o novo envase presenta unha menor variabilidade.

Desta análise pódese concluír que as melloras en dimensións como a funcionalidade, a hermeticidade e a hixiene lle engaden máis valor ao produto e lle confiren unha diferenciación superior. Esa mellora na proposta de valor permite que a marca non só poida conseguir unhas mellores condicións de negociación cos distribuidores, senón que sexa potencialmente máis valorada e recoñecida fronte ás alternativas que compiten no mercado, especialmente as marcas de distribuidor. Igualmente, o con- 
sumidor valora a diferenciación superior do produto, que se reflicte na disposición a pagar un prezo relativamente superior. Este enfoque de marca innovadora, que permite non só conseguir unha diferenciación exitosa de produtos senón mellorar unha posición de liderado, foi contrastado empiricamente por Gehlhar, Regmi, Stefanou e Zoumas (2009).

Doutra banda, un estudo centrado en investigar os factores explicativos da intención de compra do azucre de coco, que se efectuou nos Emiratos Árabes Unidos (Nurhayati, 2018), tamén concluíu a importancia do envase fronte a outros atributos como a calidade ou o prezo.

Táboa 5. Media da intención de compra do envase de azucre tradicional (bolsa de papel) e do novo envase (brik) e test de diferenza de medias ( $t$ student), $(n=201)$

\begin{tabular}{ccc}
\hline $\begin{array}{c}\text { Media da intención de compra } \\
\text { do envase brik e desviación estándar }\end{array}$ & $\begin{array}{c}\text { Media da intención de compra } \\
\text { do envase de bolsa papel e desviación estándar }\end{array}$ & $\begin{array}{c}\text { Diferenza } \\
\text { de medias }\end{array}$ \\
\hline $6,16(0,982)$ & $3,83(1,490)$ & $2,33^{*}$ \\
\hline
\end{tabular}

Nota: *Rexéitase a hipótese nula $\left(\mathrm{H}_{0}\right.$ : non hai diferenza na intención de compra da bolsa de papel e do envase brik). Fonte: elaboración propia.

\subsubsection{Disposición a pagar}

No tocante á disposición a pagar (Táboa 6), a media da disposición a pagar do novo envase (brik) é estatisticamente superior ao envase tradicional (bolsa de papel), feito que se pode comprobar ao ver que a diferenza en termos absolutos é grande $(0,15 €)$ e que o nivel de significación é inferior ao $5 \%$ $(p<0,05)$. Polo tanto, este resultado ratifica que os novos atributos confiren un valor engadido que se concreta nunha maior funcionalidade, hermeticidade e hixiene, o que se traduce nunha predisposición a pagar un sobreprezo fronte ao envase tradicional.

Táboa 6. Media da disposición a pagar do envase de azucre tradicional (bolsa papel) e do novo envase (brik) test de diferenza de medias ( $\mathrm{t}$ student), $(\mathrm{n}=201)$

\begin{tabular}{ccc}
\hline $\begin{array}{c}\text { Media da disposición a pagar } \\
\text { polo envase brik (en euros) }\end{array}$ & $\begin{array}{c}\text { Media da disposición a pagar } \\
\text { pola bolsa de papel. Prezo de referencia en euros }\end{array}$ & $\begin{array}{c}\text { Diferenza } \\
\text { de medias }\end{array}$ \\
\hline $0,84 €$ & $0,69 €$ & $0,15 €^{*}$ \\
\hline
\end{tabular}

Nota: *Rexéitase a hipótese nula ( $\mathrm{H}_{0}$ : non hai diferenza na disposición a pagar entre a bolsa de papel e o envase brik). Fonte: elaboración propia.

En suma, pódese contrastar que o novo envase é máis valorado polo consumidor final, posto que mantén as características do produto, é máis manexable e tamén máis hixiénico. Este resultado é coherente coa investigación previa, onde se concluíra que un deseño mellor adaptado aos usos do consumidor permitiría non só reforzar o nome da marca senón favorecer a intención de compra ou a súa repetición (Rundh, 2009), e que os beneficios utilitarios do envasado afectarían á calidade percibida do produto (Shih-Tse Wang, 2017).

\section{Implicacións empresariais}

A principal contribución deste estudo foi contrastar empiricamente como a través da innovación é posible engadirlle valor a unha categoría de produto de baixo prezo, como é o azucre branco, non só 
para o consumidor final senón tamén para o provedor do envase (Elopak), para o fabricante (Azucarera) e para os distribuidores.

O provedor consegue abordar unha categoría que anteriormente non considerara, xa que o seu negocio se centraba nos líquidos. 0 desenvolvemento desta nova categoría ábrelle ao provedor a oportunidade de incrementar as súas vendas e os seus beneficios.

O fabricante consegue diferenciarse fronte á súa competencia. Así mesmo, consegue mellorar a imaxe do produto e da súa marca, e incrementar a fidelidade cara a esta ao resolver os principais freos para a compra de azucre mediante o envase tradicional de papel. Tamén lle permite axustarse mellor a un público obxectivo que demanda unha menor cantidade de azucre por envase, como consecuencia do incremento do número de fogares unipersoais e das tendencias de consumo que recomendan unha menor inxestión de azucre. Desta maneira, a empresa conseguiu desenvolver un novo envase que reflicte modernidade e capacidade innovadora, polo que se converte nun excelente vehículo para comunicarse co consumidor e para fortalecer o valor da marca (Silayoi e Speece, 2007).

Os distribuidores conseguen mellorar o seu beneficio tanto pola vía dos ingresos, ao vender unha nova referencia cun maior PVP, como pola vía dos custos, ao non xerar roturas nas súas tendas producidas polo envase tradicional de papel. A redución das roturas provoca unha mellor imaxe da tenda e a necesidade de menor cantidade de persoal para a súa limpeza.

Finalmente, os consumidores séntense máis satisfeitos, posto que o produto é máis fácil de manexar, máis hixiénico, máis hermético e cun sistema de tapa de parafuso de apertura e peche. Estas novas características non só permiten que o azucre se conserve mellor senón que tamén melloran notablemente o manexo do recipiente.

\section{Conclusións}

O obxectivo desta investigación foi analizar se doce anos despois do lanzamento dun novo envase de azucre branco para consumo no fogar este segue configurándose como unha fonte de valor para o consumidor final. Puido comprobarse que o novo envase, que é máis fácil de manexar, máis hixiénico, máis hermético e cun sistema de apertura e peche máis funcional, presenta un valor significativamente superior ao envase tradicional. Estas novas características permiten que o azucre se conserve mellor, ao tempo que melloran sensiblemente o manexo do envase. Esta embalaxe, ademais de ser moito máis manexable, permite que as propiedades do produto se conserven mellor. Por conseguinte, os aspectos funcionais mostran vantaxes competitivas no envase brik, destacando especialmente en resistencia, impermeabilidade e facilidade de apertura e peche, que son as principais debilidades do envase tradicional de azucre branco.

En ausencia de información sobre o prezo, o envase de azucre branco alcanza unha intención de compra media superior á bolsa actual de 1 quilo $(6,16$ vs. 3,83). En canto ao prezo, o que os consumidores están dispostos a pagar polo brik son 0,84 euros de media, o que supón un incremento significativo sobre o prezo do azucre branco en papel. Por conseguinte, o desenvolvemento de novos formatos que se adapten mellor aos consumidores é unha forma de desenvolver un maior valor para o consumidor. En definitiva, a mellora e desenvolvemento de novos envases ou formatos de presentación é unha excelente oportunidade para a industria azucreira. Estes novos formatos de presentación tamén permitirán conservar o azucre durante máis tempo. Finalmente, existe unha oportunidade implícita para descubrir novos formatos de presentación para o mercado industrial e a restauración.

\section{Limitacións e futuras liñas de investigación}

Cómpre destacar a limitación de poder facer a investigación de mercado nun contexto real de compra onde se puidese comparar non só as diferentes alternativas que existen de marcas de fabricante -entre as que se atopa esta marca- e marcas de distribuidor, senón tamén as variables de promoción e 
localización preferente no lineal. Así mesmo, a realización deste estudo permitiría abordar con maior profundidade outros targets non considerados inicialmente no lanzamento como, por exemplo, os inmigrantes. 0 elevado custo de abordar unha investigación de mercado destas dimensións en todo o territorio de España impediu realizar ese estudo.

Doutra banda, esta investigación deixa abertas novas liñas de investigación futuras, como é a posibilidade de desenvolver novos formatos de presentación así como o perfeccionamento de novos envases brik para outras categorías de produto.

\section{Bibliografía}

Arsil, P., Li, E., Bruwer, J. e Lyons, G. (2014). Exploring consumer motivations towards buying local fresh food products: A means-end chain approach. British Food Journal, 116(10), 1533-1549.

DOI: https://doi.org/10.1108/BFJ-04-2013-0083

Azad, N. e Masoumi, M. (2012). The impact of packaging on product competition. Management Science Letters, 2(8), 2789-2794. DOI: https://doi.org/10.5267/j.msl.2012.10.008

Barrena, R. e Sánchez, M. (2010). Frequency of consumption and changing determinants of purchase decision: From attributes to values in the organic food market. Spanish Journal of Agricultural Research, 8(2), 251-272. DOI: https://dx.doi.org/10.5424/sjar/2010082-1178

Belkova, J., Rozkot, M., Danek, P., Klein, P., Matonohova, J. e Podhorna, I. (2017). Sugar and nutritional extremism. Critical Reviews in Food Science and Nutrition, 57(5), 933-936. DOI: https://doi.org/10.1080/10408398.2014.940027

Bello Acebrón, L. e Calvo Dopico, D. (2000). The importance of intrinsic and extrinsic cues to expected and experienced quality: An empirical application for beef. Food Quality and Preference, 11(3), 229-238. DOI: https://doi.org/10.1016/S0950-3293(99)00059-2

Blattberg, R. (1995). Category management guides: ... A series of implementation guides. Washington DC, WA: Food Marketing Institute.

Bonke, J. (1992). Choice of foos-allocation of time and money, household production and market services. MAPP Working Paper No. 3. Copenhagen, Sweden: MAPP.

Recuperado de: http://pure.au.dk/portal/files/32299487/wp03.pdf

Calvo Dopico, D., Tudoran, A. e Olsen, S. O. (2010). Análisis de las preferencias de un nuevo producto de conveniencia a base de pescado. Revista Española de Estudios Agrosociales y Pesqueros, 225, 71-108. DOI: https://doi.org/10.22004/ag.econ.186040

Casares Ripol, J., Martín Cerdeño, V. J. e Aranda García, E. (2000). Vértigo en la distribución comercial, concentración, competencia, empleo y relaciones con proveedores. Distribución y Consumo, 10(49), 5-26. Recuperado de: https://www.mapa.gob.es/ministerio/pags/biblioteca/revistas/pdf DYC/DYC 1999 49 4 22.pdf

Charters, S. e Pettigrew, S. (2003). The intrinsic dimensions of wine quality: An exploratory investigation. En: L. Lockshin y C. Rungie (Eds.), Proceedings of the International Colloquium in Wine Marketing 2003. Adelaide, South Australia. Adelaide, South Australia: University of South Australia, Wine Marketing Research Group. Recuperado de: https://pdfs.semanticscholar.org/fc2c/662ef0a87021e85c56d1e4a0de6dc284652d.pdf

Chernev, A. (2003). When more is less and less is more: The role of ideal point availability and assortment in consumer choice. Journal of Consumer Research, 30(2), 170-183. DOI: https://doi.org/10.1086/376808

Chironi, S., Bacarella, S., Altamore, L. e Ingrassia, M. (2017). Quality factors influencing consumer demand for small fruit by focus group and sensory test. Journal of Food Products Marketing, 23(8), 857-872. DOI: https://doi.org/10.1080/10454446.2017.1244791

Cooper, R. G. (1990). Stage-Gate systems: A new tool for managing new products. Business Horizons, 33(3), 44-54. DOI: https://doi.org/10.1016/0007-6813(90)90040-i

Cooper, R. G. (1994). Third-Generation product processes. Journal of Product Innovation Management, 11(1), 3-14. DOI: https://doi.org/10.1111/1540-5885.1110003

Cruz Roche, I. (1999). Los canales de distribución de productos de gran consumo. Concentración y competencia. Madrid: Pirámide. Recuperado de: https://www.edicionespiramide.es/libro.php?id=138584\#

Dhar, S. K., Hoch, S. J. e Kumar, N. (2001). Effective category management depends on the role of the category. Journal of Retailing, 77(2), 165-184. DOI: https://doi.org/10.1016/S0022-4359(01)00045-8

Drèze, X., Hoch, S. J. e Purk, M. (1994). Shelf management and space elasticity. Journal of Retailing, 70(4), 301-326. DOI: https://doi.org/10.1016/0022-4359(94)90002-7 
Fernández del Hoyo, A. (2009). Innovación y gestión de nuevos productos. Una visión estratégica y práctica. Madrid: Pirámide. Recuperado de: https://www.edicionespiramide.es/libro.php?id=1401061

Gehlhar, M. J., Regmi, A., Stefanou, S. E. e Zoumas, B. L. (2009). Brand leadership and product innovation as firm strategies in global food markets. Journal of Product \& Brand Management., 18(2), 115-126. DOI: https://doi.org/10.1108/10610420910949013

Gruen, T. W. e Shah, R. H. (2000). Determinants and outcomes of plan objectivity and implementation in category managament relationships. Journal of Retailing, 76(4), 483-510.

DOI: https://doi.org/10.1016/S0022-4359(00)00041-5

Howieson, J., Lawley, M. e Selen, W. (2014). New product development in small food enterprises. Journal of New Business Ideas \& Trends, 12(1), 11-26. Recuperado de: https://espace.curtin.edu.au/bitstream/handle/20.500.11937/38666/226269 146426_JNBIT_Howieson_La wley Selen 121 2014.pdf?sequence=2\&isAllowed=y

Ingrassia, M., Sgroi, F., Tudisca, S. e Chironi, S. (2017). Study of consumer preferences in regard to the Blonde Orange Cv Washington Navel “Arancia Di Ribera PDO”. Journal of Food Products Marketing, 23(7), 799-816. DOI: https://doi.org/10.1080/10454446.2016.1164102

Jiménez-Guerrero, J. F., Gázquez-Abad, J. C., Huertas-García, R. e Mondéjar-Jiménez, J. A. (2012). Estimating consumer preferences for extrinsic and intrinsic attributes of vegetables. A study of German consumers. Spanish Journal of Agricultural Research, 10(3), 539-551. DOI: http://dx.doi.org/10.5424/sjar/2012103-342-11

Kamarulzaman, N., Jamal, K., Vijayan, G. e Ab. Jalil, S. (2014). Will consumers purchase stevia as a sugar substitute?: An exploratory study on consumer acceptance. Journal of Food Products Marketing, 20(sup1), $122-139$. DOI: https://doi.org/10.1080/10454446.2014.921877

Min Han, C. (1989). Country image: Halo or summary construct? Journal of Marketing Research, 26(2), 222-229. DOI: https://doi.org/10.1177/002224378902600208

Ministerio de Agricultura, Pesca y Alimentación. (2019). Informe del consumo alimentario en España 2018. Madrid: MAPA. Recuperado de: https://www.mapa.gob.es/images/es/20190807 informedeconsumo2018pdf tcm30-512256.pdf

Myrland, Ø., Trondsen, T., Johnston, S., R. e Lund, E. (2000). Determinants of seafood consumption in Norway: Lifestyle, revealed preferences, and barriers to consumption. Food Quality and Preference, 11(3), 169-188. DOI: https://doi.org/10.1016/S0950-3293(99)00034-8

Nurhayati, R. (2018). Factors influencing the purchase intention of coconut sugar, towards product quality, price and packaging in UAE market. (Doctoral dissertation). Surabaya, Java Oriental: Universitas Ciputra.

Olsen, S. O., Scholderer, J., Bruns $\varnothing$, K. e Verbeke, W. (2007). Exploring the relationship between convenience and fish consumption: A cross-cultural study. Appetite, 49(1), 84-91. DOI: https://doi.org/10.1016/i.appet.2006.12.002

Rojas-Méndez, J. I., Le Nestour, M. e Rod, M. (2015). Understanding attitude and behavior of Canadian consumers toward organic wine. Journal of Food Products Marketing, 21(4), 375-396. DOI: https://doi.org/10.1080/10454446.2014.885869

Rouquet, L. e Valenzuela Martínez, A. (1998). La gestión por categorías: los componentes del éxito. Harvard Deusto Marketing \& Ventas, 28, 52-55.

Rundh, B. (2009). Packaging design: Creating competitive advantage with product packaging. British Food Journal, 111(9), 988-1002. DOI: https://doi.org/10.1108/00070700910992880

Russell, G. J. (2010). Itemized rating scales (Likert, Semantic Differential, and Stapel). Wiley International Encyclopedia of Marketing, 1-9. DOI: https://doi.org/10.1002/9781444316568.wiem02011

Sansalvador Sellés, M. E. (2001). La importancia del coste total de la calidad como instrumento de gestión. Técnica Contable, 53(628), 265-278. Recuperado de: http://iggomez.eu/z\%20Privado/b\%20usuarios/nrevista/caja/3tc/2001/628.pdf

Shih-Tse Wang, E. (2017). Different effects of utilitarian and hedonic benefits of retail food packaging on perceived product quality and purchase intention. Journal of Food Products Marketing, 23(3), 239-250.

DOI: https://doi.org/10.1080/10454446.2014.885867

Silayoi, P. e Speece, M. (2007). The importance of packaging attributes: A conjoint analysis approach. European Journal of Marketing, 41(11/12), 1495-1517. DOI: https://doi.org/10.1108/03090560710821279

Steenkamp, J. B. (1986). Perceived quality of food products and its relationship to consumer preferences: Theory and measurement 1. Journal of Food Quality, 9(6), 373-373.

DOI: https://doi.org/10.1111/j.1745-4557.1986.tb00807.x

Steenkamp, J. B. (1993). Food consumption behavior. European Advances in Consumer Research, 1, $401-409$. 
Sveinsdóttir, K. (2006). The young consumer: Attitudes and fish consumption. Icelandic Fisheries Laboratories, Working Paper. Reykjavik, Islandia: Icelandic Fisheries Laboratories (IFL).

Tam, J. L. M. (2004). Customer satisfaction, service quality and perceived value: An integrative model. Journal of Marketing Management, 20(7-8), 897-917. DOI: https://doi.org/10.1362/0267257041838719

Tiozzo, B., Mari, S., Ruzza, M., Crovato, S. e Ravarotto, L. (2017). Consumers' perceptions of food risks: A snapshot of the Italian Triveneto area. Appetite, 111(1), 105-115. DOI: https://doi.org/10.1016/j.appet.2016.12.028

Van den Berg, V. L. (2011). Current opinion: Is added dietary sugar detrimental to health? South African Family Practice, 53(3), 257-261. DOI: https://doi.org/10.1080/20786204.2011.10874095

Wierenga, B. (1983). Model and measurement methodology for the analysis of consumer choice of food products 1. Journal of Food Quality, 6(2), 119-137. DOI: https://doi.org/10.1111/j.1745-4557.1983.tb00761.x

Yagüe Guillén, M. J., Cruz Roche, I. e Rebollo Arévalo, A. (2003). Concentración y competencia en los canales de distribución de productos alimenticios. Papeles de Economía Española, 96, 112-133. Recuperado de: http://www.funcas.es/publicaciones new/

Zeithaml, V. A. (1988). Consumer perceptions of price, quality, and value: A means-end model and synthesis of evidence. Journal of Marketing, 52(3), 2-22. DOI: https://doi.org/10.1177/002224298805200302 